\title{
A role for the serotonin transporter in hypoxia- induced pulmonary hypertension
}

\author{
Barry L. Fanburg and Sheu-Ling Lee \\ Pulmonary and Critical Care Division, New England Medical Center, Boston, Massachusetts, USA \\ Address correspondence to: Barry L. Fanburg, Pulmonary and Critical Care Division, \\ New England Medical Center, 750 Washington Street, \#257, Boston, Massachusetts 02111, USA. \\ Phone: (617) 636-5871; Fax: (617) 636-5953; E-mail: bfanburg@lifespan.org.
}

Serotonin (5-hydroxytryptamine; 5-HT) is one of many vasoactive substances postulated to participate in the development of hypoxia-induced pulmonary hypertension. Pulmonary vasoactive responses to hypoxia are intensified by 5 HT (1), but attempts to block hypoxiainduced pulmonary hypertension with 5-HT receptor antagonists have met with mixed success. Furthermore, it has been difficult to establish a causal relationship between 5-HT and the physiological response to hypoxia. Lacking in much of this work is a clear distinction between two classes of molecules, 5-HT transporters and 5-HT receptors, either or both of which may participate in the response of pulmonary vascular smooth muscle cells to 5-HT.

High levels of 5-HT have been associated with pulmonary hypertension in several systems. Herve et al. (2) described a patient with pulmonary hypertension who had high levels of circulating 5-HT due to a platelet storage disease, and other individuals have been described with primary pulmonary hypertension associated with elevated serum 5-HT levels (3). In the fawnhooded rat, an animal model for platelet storage disease that exhibits high circulating levels of 5-HT, mild hypoxia also leads to pulmonary hypertension (4, 5). Finally, pulmonary hypertension is also associated with appetite suppressants, such as fenfluramine or dexfenfluramine, which block reuptake of 5-HT.

\section{Transduction of 5-HT signals through the serotonin transporter and the 5-HT receptors}

Several subtypes of signal-transducing 5-HT receptors have been characterized pharmacologically and cloned (see review in ref. 6). Depending on their subtype, these receptors may act on Gproteins and thereby activate phospholipase $\mathrm{C}$ or adenylate cyclase (6). By analogy with other signaling molecules, it is generally assumed that these receptors operate at the cell surface, without necessarily mediating the uptake of 5HT. In addition, 5-HT may be internalized into a variety of cell types, including platelets, neurons, mast cells, endothelial cells, and smooth muscle cells, through an active transport mechanism that is powered by a transmembrane $\mathrm{Na}^{+} / \mathrm{Cl}^{-}$gradient $(7)$. Transporter genes have been cloned in rat, human, mouse, bovine, and Drosophilia (8-13). The serotonin transporter (SERT) belongs to a large family of sodium chloride-dependent $\gamma$-aminobutyric acid/norepinephrine transporters. The precise relationship between 5-HT receptors and the transporter has never been adequately defined. Some cells appear to contain receptors, others transporters, and some both.

Both bovine pulmonary artery endothelial and smooth muscle cells actively transport 5-HT $(14,15)$, and this transport is enhanced by exposure of cells to hypoxia $(15,16)$. Hypoxia also activates the mitogen-activated protein (MAP) kinase (17), thereby inducing c-fos transcription, which leads to activation of hypoxia-inducible

Cellular transduction pathways for $5-\mathrm{HT}$

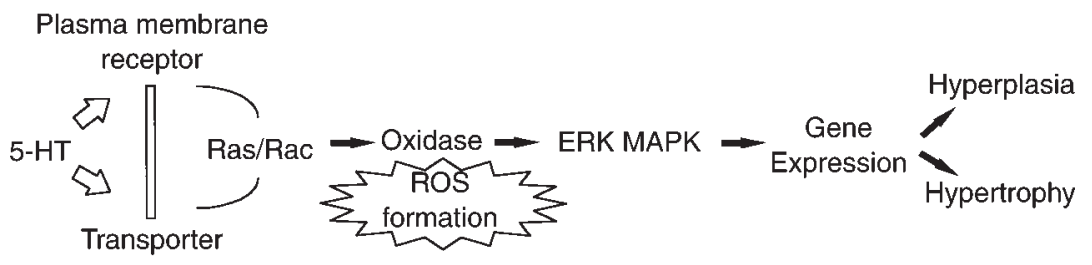

\section{Figure 1}

Stimulation begins with contact between 5-HT and either a transporter or receptor, which may lead to activation of Ras or Rac or both. The signal then activates a NAD (P)H oxidase that has not been fully characterized, leading to release of reactive oxygen species (ROS) and the activation of the ERK1 or ERK2 MAP kinases. The consequent changes in gene expression culminate in both cellular hyperplasia and hypertrophy. 
(extracellular signal-regulated kinase1/-2) MAP kinase - to induce smooth muscle cell hyperplasia or hypertrophy (Figure 1) (23-25). These signals occur only in intact cells, not in cellular homogenates (23). Although bovine pulmonary artery endothelial cells actively transport 5-HT, they neither proliferate nor induce protein tyrosine phosphorylation in response to this stimulus (23). We previously demonstrated that Chinese hamster lung fibroblasts respond to 5-HT through both SERT and a 5-HT2 receptor, leading to both transmembrane signaling and proliferation (25). Similarly, in rat mesangial cells, 5-HT activates a 5HT2A receptor through a Gq-protein-coupled pathway, leading to activation of phospholipase $\mathrm{C}, \mathrm{NAD}(\mathrm{P}) \mathrm{H}$ oxidase, and ERK MAP kinase $(26,27)$.

In Chinese ovary fibroblasts expressing an exogenous 5-HT1A receptor, 5HT also activates NAD(P)H oxidase, ROS formation, and the ERK MAP kinase through a Gi-protein-mediated pathway (28). Humblot et al. reported that, in PC12 cells, 5-HT induces tyrosine phosphorylation and subsequently activates TIS8/egr-1 and c-fos expression (29). Furthermore, Nebigil and colleagues recently showed that the 5-HT2B receptor stimulates cyclin-dependent kinase activities by at least two mechanisms: it acts through c-Src and the receptor tyrosine kinase platelet-derived growth factor receptor (PDGFR) to stimulate cyclin D1/cdk4 activity, and it acts through c-Src alone to stimulate cyclin E/cdk2 (30). However, since SERT and 5-HT receptors may coexist in a single cell type, it remains possible that some of these effects require SERT rather than the 5-HT receptor. Nevertheless, it appears that activation of either SERT or receptor by 5 HT, depending upon cell type, can initiate a signaling process that activates cell proliferation (Figure 1).

\section{SERT in the pulmonary response to hypoxia}

These observations raise fundamental questions about the functions of 5-HT receptors and transporters: Do 5-HT receptors internalize 5-HT? Do receptors and transporters expressed in the same cell interact, and, if so, how? Resolution of these issues is complicated by the long-standing assumption in the literature that 5 -HT receptors, rather than transporters, stimulate proliferation (6). The article by Eddahibi and associates in this issue of the JCI (31) follows closely on their recent work (32) showing that hypoxia in rats upregulates SERT mRNA. Now these authors find that mutant mice lacking this transporter are protected from developing pulmonary hypertension. After excluding the possibility that hypoxic pulmonary hypertension is reduced in mutant mice because of attenuation of acute pressure changes, Eddahibi et al. argue that the 5-HT transporter is required directly in the development of this condition (31). The present data are consistent with the thesis that remodeling of the pulmonary circulation, either as a result of or contributor to increased pulmonary vascular pressure, depends on the presence of SERT. They also fit with in vitro data showing that 5-HT causes vascular smooth muscle cell proliferation and that hypoxia enhances the uptake of 5-HT $(15,21,22)$. 5-HT in the circulation, probably released from platelets, likely provides the substrate for the 5-HT transporter. This hypothesis can also account for dexfenfluramine-associated pulmonary hypertension, since this drug stimulates release of 5 -HT from platelets and neurons, inhibits 5-HT reuptake by platelets (33), and acts through similar signaling pathways as 5-HT to stimulate smooth muscle cell proliferation directly (S.-L. Lee et al., unpublished data).

A better conceptual framework is still needed regarding the structural identities of or relationships between the 5HT receptor and the 5-HT transporter. More complete information is needed about the precise cellular signaling pathways of 5-HT. Perhaps most importantly, the oxidase that serves as an intermediate in this pathway and the specific ROS it generates must be characterized more fully. Finally, as a corollary, it should be determined whether any of the components of the signaling pathways could be blocked to prevent or reverse pulmonary hypertension for therapeutic benefit.

\section{Acknowledgments}

Studies of the authors have been supported by a research grant from the National Heart, Lung, and Blood Institute of the National Institutes of Health (HL-32723).
1. Eddahibi, S., et al. 1997. Treatment with 5-HT potentiates development of pulmonary hypertension in chronically hypoxic rats. Am. J. Physiol. 272:H1173-H1181

2. Herve, P., et al. 1990. Primary pulmonary hypertension in a patient with a familial platelet storage pool disease: role of serotonin. Am. J. Med. 89:117-120.

3. Herve, P., et al. 1995. Increased plasma serotonin in primary pulmonary hypertension. Am. J. Med. 99:249-254.

4. Tschopp, T.B., and Zucker, M.B. 1972. Hereditary defect in platelet function in rats. Blood. 40:217-226.

5. Sato, K., et al. 1992. Factors influencing the idiopathic development of pulmonary hypertension in the fawn hooded rats. Am. Rev. Respir. Dis. 145:793-797.

6. Fanburg, B.L., and Lee, S.L. 1997. A new role for an old molecule: serotonin as a mitogen. Am.J. Physiol. 272:L795-L806.

7.Junod, A.F. 1972. Uptake metabolism and efflux of ${ }^{14} \mathrm{C}$-5-hydroxytryptamine in isolated perfused rat lungs. J. Pharmacol. Exp. Ther. 183:341-355.

8. Blakely, R.D., et al. 1991. Cloning and expression of a functional serotonin transporter from rat brain. Nature. 354:66-70.

9. Corey, J.L., Quick, M.W., Davidson, N., Lester, H.A., and Guastella, J. 1994. A cocaine-sensitive Drosophila serotonin transporter: cloning, expression, and electrophysiological characterization. Proc. Natl. Acad. Sci. USA. 91:1188-1192.

10. Demchyshyn, L.L., et al. 1994. Cloning expression and localization of a chloride-facilitated cocainesensitive serotonin transporter from Drosophila melanogaster. Proc. Natl. Acad. Sci. USA. 91:5158-5162.

11. Hoffman, B.J., Mezey, E., and Brownstein, M.J. 1991. Cloning of a serotonin transporter affected by anti-depressants. Science. 254:579-580.

12. Mortensen, O.V., Kristensen, A.S., Rudnick, G., and Wiborg, O. 1999. Molecular cloning, expression and characterization of a bovine serotonin transporter. Brain Res. Mol. Brain Res. 71:120-126.

13. Ramamoorthy, S., et al. 1993. Antidepressantand cocaine-sensitive human serotonin transporter: molecular cloning, expression and chromosomal localization. Proc. Natl. Acad. Sci. USA. 90:2542-2546.

14. Lee, S.L., and Fanburg, B.L. 1986. Serotonin uptake by bovine pulmonary artery endothelial cells in culture. I. Characterization. Am. J. Physiol. 250:C761-C765.

15. Lee, S.L., Dunn, J., Yu, F.S., and Fanburg, B.L. 1989. Serotonin uptake and configuration change of bovine pulmonary artery smooth muscle cells in culture. J. Cell. Physiol. 138:145-153.

16. Lee, S.L., and Fanburg, B.L. 1986. Serotonin uptake by bovine pulmonary artery endothelial cells in culture. II. Stimulation by hypoxia. Am.J. Physiol. 250:C766-C770.

17. Muller, J.M., Krauss, B., Kaltschmidt, C., Baeuerle, P.A., and Ruper, R.A. 1997. Hypoxia induces cfos transcription via a mitogen-activated protein kinase-dependent pathway. J. Biol. Chem. 272:23435-23439.

18. Minet, E., et al. 2000. ERK activation upon hypoxia: involvement in HIF-1 activation. FEBS Lett. 18:53-58.

19. Lee, S.L., and Fanburg, B.L. 1992. Serotonin produces a configurational change of cultured smooth muscle cells that is associated with elevation of intracellular cAMP. J. Cell. Physiol. 150:396-405

20. Becker, B.N., et al. 1992. 8-hydroxy-2-(di-n-propylamino)tetralin-responsive 5-hydroxytryptamine4-like receptor expressed in bovine pulmonary artery smooth muscle cells. Mol. Pharmacol. 42:817-825.

21. Lee, S.L., Wang, W.W., Moore, B.J., and Fanburg, B.L. 1991. Dual effect of serotonin on growth of bovine pulmonary artery smooth muscle cells in 
culture. Circ. Res. 68:1362-1368.

22. Lee, S.L., Wang, W.W., Lanzillo, J.J., and Fanburg, B.L. 1994. Serotonin produces both hyperplasia and hypertrophy of bovine pulmonary artery smooth muscle cells in culture. Am. J. Physiol. 266:L46-L52.

23. Lee, S.L., Wang, W.W., and Fanburg, B.L. 1997. Association of Tyr phosphorylation of GTPaseactivating protein with mitogenic action of serotonin. Am. J. Physiol. 272:C223-C230.

24. Lee, S.L., Wang, W.W., and Fanburg, B.L. 1998. Superoxide as an intermediate signal for serotonin-induced mitogenesis. Free Radic. Biol. Med. 24:855-858.

25. Lee, S.L., Wang, W.W., Finlay, G.A., and Fanburg, B.L. 1999. Serotonin stimulates mitogen-activated protein kinase activity through the formation of superoxide anion. Am. J. Physiol. 277:L282-L291.
26. Greene, E.L., et al. 2000. 5-HT(2A) receptors stimulate mitogen-activated protein kinase via $\mathrm{H}_{2} \mathrm{O}_{2}$ generation in rat renal mesangial cells. Am. J. Physiol. Renal Physiol. 278:F650-F658.

27. Watts, S.W. 1998. Activation of the mitogen-activated protein kinase pathway via the 5-HT2A receptor. Ann. NY Acad. Sci. 861:162-168.

28. Mukhin, Y.V., et al. 2000. 5-hydroxytryptamine 1A receptor/Gi betagamma stimulates mitogen-activated protein kinase via $\mathrm{NAD}(\mathrm{P}) \mathrm{H}$ oxidase and reactive oxygen species upstream of Src in Chinese hamster ovary fibroblasts. Biochem. J. 347:61-67.

29. Humblot, N., Esteve, L., Burgun, C., Aunis, D., and Zwiller, J. 1997. 5-hydroxytryptamine induces TIS8/erg-1 and c-fos expression in PC12 cells. Involvement of tyrosine protein phosphorylation. Eur. J. Neurosci. 9:84-92.
30. Nebigil, C.G., Launay, J.M., Hickel, P., Tournois, C., and Maroteaux, L. 2000. 5-hydroxytryptamine 2B receptor regulates cell-cycle progression: crosstalk with tyrosine kinase pathways. Proc. Natl. Acad. Sci. USA. 97:2591-2596.

31. Eddahibi, S., et al. 2000. Attenuated hypoxic pulmonary hypertension in mice lacking the 5 hydroxytryptamine transporter gene. J. Clin. Invest. 105:1555-1562

32. Eddahibi, S., et al. 1999. Induction of serotonin transporter by hypoxia in pulmonary vascular smooth muscle cells: relationship with the mitogenic action of serotonin. Circ. Res. 84:329-336.

33. Buczko, W., De Gaetano, G., and Garattini, S 1975. Effect of fenfluramine on 5-hydroxytryptamine uptake and release by rat blood platelets. Br. J. Pharmacol. 53:563-568. 